\title{
A!
}

This is an electronic reprint of the original article.

This reprint may differ from the original in pagination and typographic detail.

Jalonen, Meri; Ristimäki, Päivi; Toiviainen, Hanna; Pulkkis, Anneli; Lohtander, Mika

\section{Between product development and mass production}

Published in:

Journal of Workplace Learning

DOI:

10.1108/JWL-04-2014-0027

Published: 08/02/2016

Document Version

Peer reviewed version

Please cite the original version:

Jalonen, M., Ristimäki, P., Toiviainen, H., Pulkkis, A., \& Lohtander, M. (2016). Between product development and mass production: Tensions as triggers for concept-level learning. Journal of Workplace Learning, 28(1), 3348. https://doi.org/10.1108/JWL-04-2014-0027

This material is protected by copyright and other intellectual property rights, and duplication or sale of all or part of any of the repository collections is not permitted, except that material may be duplicated by you for your research use or educational purposes in electronic or print form. You must obtain permission for any other use. Electronic or print copies may not be offered, whether for sale or otherwise to anyone who is not an authorised user. 
Author's Accepted Manuscript (Final, peer-reviewed version Aug-2015)

Published in the Journal of Workplace Learning, Vol. 28 No. 1, 2016, pp. 33-48

http://dx.doi.org/10.1108/JWL-04-2014-0027

\title{
Between product development and mass production: Tensions as triggers for concept-level learning
}

\author{
Meri Jalonen ${ }^{1}$, Päivi Ristimäki ${ }^{2}$, Hanna Toiviainen ${ }^{2}$, Anneli Pulkkis ${ }^{1}$, Mika Lohtander $^{3}$ \\ ${ }^{1}$ Aalto University, Finland \\ ${ }^{2}$ University of Helsinki, Finland \\ ${ }^{3}$ Lappeenranta University of Technology, Finland
}

\section{Structured abstract}

Purpose: The article analyzes learning in organizational transformations by focusing on concept-level tensions faced in two young companies, which were searching for a reorientation of activity with a production network between innovative product development and efficient mass production.

Design/methodology/approach: An intervention-based research project was carried out with two manufacturing companies. The data originate from workshops, whose aim was to identify learning needs based on the discussion of practices of networked production. Concept-level learning is analyzed by examining the dynamic relationships between production concepts and product concepts.

Findings: The most influential concept-level tension stemmed from the co-existence of two production concepts, product development and mass production, which manifested as ambiguity about proper actions in the production network. Other focal tensions were identified between the production and product concepts and within the companies' network 
relationships. The dominance of the mass production concept restricted the envisioning of new modes of collaboration and mutual learning in the production network.

Research limitations/implications: The workshop participants did not include representatives from the case companies' production network. Nevertheless, researchers brought the network partners' conceptions into the workshop discussion through the presented mirror data.

Practical implications: Companies striving to develop novel production concepts that call for continuous collaboration with customers and suppliers need forums for mutual learning to create solutions to concept-level tensions.

Originality/value: Companies may develop two production concepts over lengthy periods. The tensions that manifest due to incoherent guiding logics may be overcome by engaging in incremental and expansive concept-level learning, directed at the identification of relationships between production and product concepts.

Keywords: Production concept, Product concept, Tension, Transformation, Network, Learning interventions, Activity theory, Practice-based approach, Mass production, Product development

\section{Introduction}

Today's companies may choose among a wide variety of production concepts that should help them operate in global markets. These concepts typically emphasize the companies' capability to respond quickly to the preferences of customers and to establish partnerships with suppliers as a way to improve the value of their products in customers' eyes (Duguay et $a l ., 1997)$. The transition from an old production concept to a new and more efficient one is often described as implementation of a set of management instruments, such as "toolbox lean" for adopting a lean production concept (Pettersen, 2009). However, the move from one production concept to another may be seen as a tension-laden learning process (Virkkunen, 2006a) implying a profound change in the companies' work practices, not least in relationships with customers and suppliers. This article analyzes tensions and learning in two 
young companies that were moving from research intensive product development towards commercial mass production. This move represented a concept-level transformation challenging the companies as well as their network partners to develop their practices.

We draw on our intervention-based research project, which explored the development of learning-based concepts for networked production in two companies. Research collaboration with the companies was organized in two phases. In the data collection phase, we studied work practices in different phases of product development projects, involving employees both from the case companies and their network partners. In the development phase, we used the collected data to examine the production concepts of the companies together with company participants and to develop work practices and tools to better master the networked production. Between these two phases, we carried out a feedback workshop in each company. These workshops aimed to identify development targets to be worked on in the second phase of the collaboration.

In the workshop dialogues, the participants responded to the researchers' observations of the activity in the companies' production networks. The dialogues revealed tensions in the participants' conceptions of the companies' products and their production, as well as of the role of network partners. We set out to study these tensions and their implications by searching answers to the questions: What kind of concept-level tensions emerge in the dialogue? How do these tensions characterize the ongoing transformation of production concepts in each company and what are their implications to concept-level learning?

We begin our article with the historical background of the case companies by focusing on challenges of their production activity. Thereafter, we review literature on production concepts and develop conceptual connections between tensions stemming from the transformation of production concepts and concept-level learning. Then, we present the research design, after which we analyze the concept-level tensions. We conclude the article by discussing what the identified tensions tell about concept-level learning and by outlining theoretical and practical implications of our research. 


\section{Transformation of production concepts in two young companies}

This research was carried out as a part of a national funding program aimed to develop competitive production concepts for Finnish manufacturing industry. We searched for two companies operating in a production network for which the development of production concepts would be a timely challenge. Both case companies that joined in the research project were struggling with transforming their activity from research and development towards commercial mass production. The research collaboration attracted them because they wanted to develop tools for mastering their networked production. We will call these companies Fipak and Enerfi.

Fipak was a novel business unit of a paper company, established as a result of several years of development to commercialize a new kind of a recyclable package. The company had wanted to create new uses for a novel paperboard material and had identified market potential in food industry's growing interest in recyclable materials. From the beginning, an essential requirement for the new package was cost-effective manufacturing. This meant production in high volumes with automatized manufacturing technology. The development of the new package and the technology involved diverse experts in the paper company and a development network of universities, suppliers and a pilot customer.

When our research project started, Fipak had launched the first commercial package, developed in collaboration with the pilot customer from the food industry. The construction of an automatized production environment was ongoing. Fipak was also starting to work with new customers to create packages for other kinds of use. All of these new projects required further elaboration of the product. Therefore, the whole team of approximately ten employees in Fipak worked intensively to solve emerging problems with the materials and the manufacturing technology. Further development of the product also called for constant collaboration with the suppliers of materials and manufacturing equipment.

Enerfi was a business unit of a technology company formed through the merger of several small engineering offices. Whereas these offices had concentrated on the design of products and relied on partners to manufacture them, the new technology company had established its own production facilities besides its research and development activity. Enerfi's products 
were complex technological assemblies forming an important component of power applications for renewable energy.

At the beginning of our research collaboration, Enerfi had only one product in mass production on the premises of two Finnish subcontractors. Enerfi was striving to establish a factory in China to be located in the growing market. Most of the projects in Enerfi were still in the phase of producing prototypes, which were to be sent to customers for field testing. During the research collaboration, Enerfi was expanding its activity: the number of employees almost doubled to approximately 150 persons and an increasing number of product development projects proceeded to a mass production phase. The company was developing a new production concept for networked mass production based on lean production principles. According to the aspired concept, Enerfi would be in charge of designing both the product and its production, as well as testing the final products; the actual manufacturing of the components and final products were to be handed over to network partners in any corner of the globe.

Even though both case companies strived to organize their activity according to a mass production concept, their local solutions in terms of division of work and relationships with network partners differed significantly. Common to the companies was the crucial role of the product in the development of their local production concepts. This research design allowed us to compare the tensions the companies faced and the solutions they developed.

\section{Concept-level tensions and learning in organizational transformation}

\section{Production concepts and product concepts}

The role of the product in the development of production concepts is mostly neglected in the literature. Production concepts are studied in the domain of operations management, which focuses on the optimization of the production process and resources (Gunasekran and Ngai, 2012), only seldom addressing the role of products in this optimization. Studies about product development typically belong to the domain of innovation management with a focus on the organization of product development process (Ravasi and Stigliani, 2012), often ignoring the 
production of the final product. The same functional separation of product development and production - planning and execution - is seen in manufacturing companies, reflecting the legacy of mass production (Duguay et al., 1997).

Another limitation of the production concept literature relates to viewing concept-level transitions as implementation of new production management instruments (Da Silveira et al., 2001; Moyano-Fuentes and Sacristán-Díaz, 2012). Scholars of workplace learning drawing on cultural-historical activity theory have highlighted the importance of learning in the development of production concepts. These researchers conceptualize the moves between production concepts in terms of transformation of activity through expansive learning (Virkkunen, 2007). Some of these analyses draw on the work of Victor and Boynton (1998) who have defined five subsequent generic modes of production work: craft, mass production, process enhancement, mass customization and co-configuration. This framework explains the transformation as an accumulation of learning within the previous production concept to be capitalized on when markets create new kinds of opportunities.

A third limitation of the literature stems from an intra-organizational orientation to the optimization of the production process, which neglects the significance of networks in production activity. Some production concepts, such as lean production, have recently expanded the scope to embrace supply networks to ensure that suppliers act according to the principles of the concept (Moyano-Fuentes and Sacristán-Díaz, 2012). However, this literature provides little understanding of how partners can learn from each other to develop products and network practices. Learning to network and learning in networks have become important aspects of learning when developing any type of production (Toiviainen, 2007).

To overcome these limitations in the current literature, we propose a practice-based and network-centered approach to production concepts. This means that we study how the logic of a production concept is manifested in daily work practices. We understand 'production' as a collection of practices to create a product, spanning from the articulation of the product requirements to the delivery of the product. Furthermore, we study network practices by focusing on collaboration across companies, which shapes their activity and learning (Miettinen et al., 2008). Hence the study of networked production focuses on the interconnected, situated actions of knowledgeable actors giving the product its form (cf. 
Nicolini et al., 2003). Theoretically, these actions are oriented according to both production concepts and product concepts adopted in the company and eventually shared by the network. We therefore argue that studying the relationships between production concepts and product concepts allows a closer analysis of the transformation of the logic of production activity in companies operating in networks.

In this article, the production concept expresses the principles of organizing the activities required to produce products in the company and its network of customers and suppliers. The production concept determines the division of work among the different partners of the production network, the aspired kinds of relationships among them, as well as the appropriate tools for the production activity and its management.

The product concept reflects the principles guiding the development of both single products and the product offering of the company as a whole. In previous literature, product concepts are understood limitedly as representations of the goals of a product development process (Seidel, 2007), bringing together recognized market needs and the capabilities of the developing company (Orihata and Watanabe, 2000). Whereas such a view considers one product concept to represent one single product, we propose that a product concept defines the qualities of a range of products that embody a comparable use for customers.

We argue that production concepts and product concepts evolve intertwined and therefore their relationships need to be studied to see how the principles inherent in the concepts direct actions. According to our interpretation, ambiguity in concept transitions stems from incoherent principles within and between production concepts and product concepts. For example, product development is often a craft type of activity, where experimentation and analysis of failures are important sources of learning. The product is developed iteratively in the form of improved prototypes, meaning that the product concept evolves as a result of learning. Mass production, in contrast, aims to produce products cost-effectively and to eliminate flaws in the production process through the standardization of work methods. Thus the product concept is also standardized to produce high volume products of optimized quality with low costs. 
We see that the concept-level inconsistencies described above produce various kinds of tensions that manifest themselves in work practices of network partners. However, for us such tensions do not represent irresolvable problems but dialectic dynamics that feature learning potential. Blackler and his colleagues (1998) emphasize that due to the complexity of these kinds of tensions, their solutions are likely to be partial and temporal. Thus companies "must expect to find themselves continually puzzling about evolving tensions, and reorganizing and rethinking" (Blackler et al., 1998, 80). The development of temporal solutions to concept-level tensions calls for dialogue and collective learning in companies and networks. Through the identification of the current logics of the production and product concepts and the clarification of their relationships, it is possible to enhance a shared orientation to work activity (Virkkunen, 2006a). We call this kind of a dialogic process of examining the dialectics of production and product concepts as concept-level learning.

We suggest that concept-level learning involves collective examination of both production and product concepts which guide work practices. In concept-level transformation, learning is characterized by a collective questioning of the current activity and construction of a new model for the activity to overcome the tensions. Learning theories define this kind of transformation-oriented construction as higher level 'learning III' (Bateson, 2000) or 'expansive learning' (Engeström, 1987). Concept-level learning emphasizes that the adoption of new guiding concepts is not merely a question of implementation but a creative process calling for a reconceptualization of the activity of the company and its network (cf. Engeström et al., 2005). The outcomes of such learning manifest themselves in novel understandings of the activity and transformed collaboration practices.

Some scholars have distinguished between conceptual and operational levels of learning (see Kim, 2004), but our notion of concept-level learning is not dichotomous. Concepts may entail both a conceptual and an operational character (Virkkunen, 2006a). In a conceptual sense, a concept has a representational meaning: it expresses the aspired logic of activity and integrates understandings concerning the activity by giving it a name. In an operational sense, the concept guides actions coherently towards mutually set objectives when its logic is embedded in daily practices that take place in the network. We thus discuss production and 
product concepts as "concepts in practice" (Hutchins, 2012), covering both the conceptual and the operational dimension.

\section{Data and methods}

\section{Data: Workshop dialogues}

The data originates from feedback workshops in Fipak and Enerfi after an eight-month data collection from different product development projects. The feedback workshop concluded the data collection phase and introduced the participants to the development phase of the research collaboration. The aim was to identify learning needs based on the examination of current practices in networked production. In the development phase that followed the feedback workshop, researchers and company participants worked together to create solutions to the identified learning needs. It consisted of further data collection and workshops and lasted eleven months. The research collaboration concluded with an evaluation workshop that brought together the two companies for mutual exchange of learning outcomes of the research collaboration.

The feedback workshops involved nine persons in Fipak and thirteen persons in Enerfi representing middle management and operative staff from all areas of the production activity, e.g. sales, product design, prototype construction, purchase, production and after sales. Perspectives of customers and other network partners were mediated to the participants through interviews which were part of the collected data.

The workshop dialogues between the researchers and the participants consisted of two parts. The first dialogue, reflective in nature, was carried out during the researchers' presentations of the "mirror data", which was based on data gathered from three to four selected product development projects of each company. The mirror data consisted of the researchers' observations of work practices in the production network, to produce a surface against which the participants could investigate and reflect on their activity (Virkkunen and Newnham, 2013). Drawing on the first dialogue, the second dialogue was of developmental nature encouraging the participants to identify learning needs related to the production concepts. 
The main themes of discussion, which were prepared by the researchers for the mirror data, included: conceptions of the product, network relationships and principles guiding actions in the production network. During the workshop dialogues, the participants expressed incoherencies in the work practices, e.g. between practices driven by customization of products and by standardization of production. Based on our learning-theoretical understanding we began to analyze these tensions to explore how they reflected the transformation between production concepts calling for learning.

\section{Method of analysis}

We conducted three rounds of analysis to identify the concept-level tensions brought up in the workshop dialogues. In the first round, we searched for dialogue episodes in which the participants addressed topics related to the production and product concepts. In the data, we identified concept-related dialogue episodes as those in which the participants characterized the products produced by the company, the ways of working with customers and other partners, etc.

In the second round, we selected for a closer analysis those concept-related episodes that expressed a tension. Concept-level tensions were identified in these episodes as comparisons: The tensions represented comparisons between current ways of working and the aspired logic of activity (production concept) and, respectively, between properties of current products and possible future products (product concept). Some tensions were explicitly articulated by the participants and easy to identify. Some tensions of less explicit nature were identified by analyzing the conflicting views that the participants expressed on a given topic. We identified in total 98 dialogue episodes addressing concept-level tensions: 55 episodes in the workshop data of Fipak and 43 episodes in the data of Enerfi.

In the third round, we categorized these 98 episodes according to the nature of the tensions first into narrower groups (e.g. tensions between a standardized product and work practices in the current production concept) and further into more general groups (e.g. tensions between product and production concepts). Then, we re-examined the categories and identified four types of generalized tensions representing the ongoing transformation in each company. We 
named one of these types the key tension; the one being fundamentally embedded in the historical situation of the given company and giving meaning to the rest of the tensions.

\section{Concept-level tensions in the case companies}

The concept-level tensions of Fipak

Fipak was moving from research-oriented product development towards commercial production of high-volume products. R\&D work continued in every new project because the products were customer-specific: the manufacturing technology needed to be tailored for each package with a different shape and the end use of a package affected the choice of materials. At the same time, these projects had commercial goals to fulfill the customers' requirements and they were limited in time and costs. Thus, we interpret that Fipak's key tension was stemming from discrepancy between two production concepts: research-oriented product development and commercial mass production. Through the mirror data, the researchers illustrated some of the differences between the production concepts to encourage discussion among the workshop participants. In excerpt 1, the sales manager expresses Fipak's goals for the development of the production concepts.

\section{Excerpt 1}

Sales manager: We strive to have those standards [standard products] that we can freely offer. But still we want to keep also the total innovation activity, not only separated from product development. But we'd still have these kinds of projects where we develop something new with a customer.

Excerpt 2 illustrates how the key tension was articulated in the dialogue. It was first formulated by one of the researchers and then taken up by the participants who further problematized it. Fipak's package designer described the feelings of not getting ahead in product development. She referred to the process of developing the first commercial package, which seemed like a series of trials-and-errors. A researcher interpreted that the researchoriented experimental activity still continued in mass production and suggested: 
Excerpt 2

Researcher: Could we think that what appears as natural in a research project and [on the contrary] when thinking that everything should happen fast and be correct at once - so [it's not natural] when aiming at mass production. So it's not natural whereas...

Sales manager: Yes, as a research project, it'd be extremely fruitful that every time you get something new to investigate.

Package designer: And I think we have indeed been talking about this together too, that there's the problem that we're still somehow in between. We should also carry out research work, but at the same time, we should already be doing sheer manufacturing.

Sales manager: Manufacturing for customers...

Package designer: ...in which we should make it work at once.

This dilemma was discussed further and summarized by the production manager:

Production manager: Yes, they are two totally different things, research and [production]. They don't work when you always need to change something. When you go to production, then everything can be completely upside down, then it isn't the way we first thought.

The second tension occurred as a mismatch between the properties of the new innovative product concept and the requirements of the mass production concept set by customers and the manufacturing technology. The hybrid package was a customizable product concept that provided differentiation through materials and environmental friendliness. However, the efficiency requirements of Fipak's mass production concept called for standardization, rather than customization, of products. Primary customers, for their part, preferred a replacing 
package, of the same shape as the former one, over a new innovative package to ensure that the package fitted their existing production lines. The customers were also reluctant to pay more for the hybrid package than for conventional packages. For Fipak, designing and producing a replacing package was demanding because they needed to adjust the manufacturing technology in a non-optimal way. Fipak's package designer expressed this tension: "If only we were allowed to design this product with this [our] technology and these materials uniquely into such a [thing] which would be good to make, then it would probably be much more gratifying to do."

The third tension appeared between two opposite modes of cooperation with customers. During the development process of the first commercial package, the Fipak team had worked in close collaboration with the pilot customer. In the product development concept, this collaborative relationship was necessary for Fipak to develop the required properties of the new package. In contrast, some other customers had limited resources to participate in package development. They expected a transaction type of relationship with Fipak delivering ready-made solutions for them, which corresponded to the mass production concept. The next excerpt illustrates reflection on the different relationships with customers.

\section{Excerpt 3}

Sales manager: The difference is that, at the outset, [the pilot customer] has had the understanding that now we're developing a new package and this requires development. Then we have ourselves marketed to these two other customers that, okay, now we're doing a replacing package [according to the dimensions of an existing package] and this is a standard package. But should we have tried to emphasize more that this also requires collaboration?

The fourth tension appeared as a mismatch between Fipak's expectations towards suppliers contributing novel ideas and its unwillingness to rely on long-term contracts with the partners. On the one hand, people in Fipak acknowledged the important contributions of their partners to the development of the hybrid package; they expected suppliers to propose improvements to the manufacturing technology. The sales manager hoped that "we would get those kinds of relationships where the opposing side would start to tell more on its own 
initiative, that it wouldn't remain a buyer-seller [relationship]." On the other hand, Fipak sought multiple replaceable suppliers to avoid dependency on a single partner.

The concept-level tensions of Enerfi

At the time of the workshop, Enerfi's production activity concentrated on customized prototypes in an early phase of customers' energy production projects. Regardless of the dominance of prototypes, Enerfi's articulated production concept focused on mass production to be implemented in the subcontractor network. The process models and tools in use served the whole product development project, concluding with a mass production phase. However, our mirror data showed that these models did not take into consideration the significant time gap and notably changing requirements between the prototype phase and the mass production phase. These changes resulted in considerable redesign compared to the first prototypes, requiring a new development process when the products finally proceeded to mass production.

Thus, we see that Enerfi's key tension was stemming from the co-existence of two production concepts: networked mass production and prototype production. This tension was discussed in the workshop, when the researchers "mirrored" the mass production concept as an ideal model that seemed to lack evidence among the data gathered from the product development projects. In excerpt 4 , the participants discuss this tension in terms of the current meaning of a prototype and zero series in Enerfi.

\section{Excerpt 4}

$\boldsymbol{R} \& \boldsymbol{D}$ engineer: Considering this ideal process, when I think about it more carefully, there's one thing that maybe is a bit differently understood. It could be that in our company, we might think differently than in other [firms]. There [on the slide] you've put that the zero series and the prototype are made at the same time.

R\&D manager: Exactly. It isn't an ideal process in my mind. 
$\boldsymbol{R} \& \boldsymbol{D}$ engineer: We've been starting to discuss this only recently because for some reason here [in Enerfi], it's done so that the prototype and the zero series are done first and only then mass production. Whereas in other places, they first make the prototype and then they start to prepare mass production. And then they make the zero series, with which they test that mass production works.

$\boldsymbol{R} \& \boldsymbol{D}$ manager: Exactly. This means that the zero series, pilot series, prepares production for the start of large-scale production. However, here [in Enerfi], it's done so that the zero series, pilot series, is always seen as one delivered to a customer and from the customer's point of view. And that isn't really according to the ideal process in my opinion.

Even though prototype production as a production concept was not acknowledged in Enerfi, its existence was reflected in the organization of product design. An engineering department was responsible for the design of customized prototypes and their later redesign for mass production, while a $\mathrm{R} \& \mathrm{D}$ department was responsible for the development of entire product concepts. The participants also pointed out that Enerfi should separate the production network according to the different needs of prototype and mass production, as expressed in the following excerpt.

\section{Excerpt 5}

Supply chain manager: What we haven't even tried so far is that we're using the same network whenever we're making the proto[type]s and a little bit serial, mass production. We should somehow differentiate the supply chain so that we have suppliers who are really concentrating on proto[type] production, and to fast delivery. And their machinery is of that kind that they are able to produce the parts in a couple of days.

We observed Enerfi's second tension between the product concept developed by the $R \& D$ department and the production concept developed by the purchase and production departments. Enerfi sought to improve the networked mass production by means of modularization and standardization of products. However, the development of a platform for 
a modular product concept and the simultaneous development of a networked production concept were carried out separately in the company, as discussed in the next excerpt. In the dialogue, the $R \& D$ manager only discusses the development of a standard product from the product concept point of view, whereas the purchaser is concerned with its translation into production practices.

\section{Excerpt 6}

$\boldsymbol{R} \& \boldsymbol{D}$ manager: Once we have a very comprehensive platform, we can easily hammer out customer products. This is the way to get closer to a standard product. When we have a platform, we'll have component solutions, sub-assemblies, whatever, just name it. We put those together in a bit different order and voilà, we have a product. And they always go to the same places [referring to the components' physical assembly in the product] the same way, they look the same, they weigh the same, they have the same functionality and they perform the same. Those are the platforms.

Researcher: Well, it's very much connected to these standardization needs and these kinds of things. So what was worrying you [the purchaser] then [in the preceding discussion] from the perspective of suppliers concerning this platform thinking?

Purchaser: That's like [the platform project] is still on the tables of the engineering and the $R \& D$ [departments]. We haven't gone through it with the zero series or anything with the production. Usually, we first try to get sub-assemblies and everything to the point of manufacturing, then we could do the whole capacity. And so far, we haven't sorted out how we're really going to do it in mass production. However, that's maybe the next phase, I hope so.

The third tension emerged between Enerfi's conceptualization of its production network as a set of collaborative partnerships and as subcontractors requiring control. While still developing the networked production concept, Enerfi already had a strong dependence on partners' knowledge in the production of components. Some participants of the workshop noted that Enerfi insufficiently took advantage of the feedback given by their network 
partners in the development of production practices in the network. On the other hand, we observed a wish to maintain control over knowledge sharing in the production network and a tendency to see the suppliers as subcontractors rather than as partners.

The fourth tension occurred between the envisioned networked production concept and the actually materialized work practices. On the one hand, the participants saw inter-functional and inter-firm collaboration necessary for the production concept to lower the costs of the products and to improve their manufacturability. On the other hand, they witnessed a functional division of labor where departments were responsible for certain phases of the production process. This was also manifested in the use of tools and procedures, which were not shared by all departments and led to coordination problems in the projects.

\section{Relationships between production concepts and product concepts}

In both of the young companies the most influential concept-level tension arose from the dynamics between two distinct but co-existing production concepts that had evolved in the company's activity. We interpret other concept-level tensions to stem from this key tension. We identified three types of tensions in the companies: 1) tensions between two historically co-existing production concepts (key tension) that encouraged different kinds of actions; 2) tensions between a product concept and a production concept; and 3) tensions stemming from inconsistent views of the mode of cooperation with network partners.

The key tensions stemmed from the presence of two co-existing production concepts. Both companies were developing a mass production concept while continuing to maintain a product development concept.

In Fipak, research-oriented product development showed characteristics of both craft and coconfiguration: development work was experimental in nature while the product properties as well as the manufacturing technology were under continuous development in collaboration with customers and suppliers (Victor and Boynton, 1998; Engeström, 2004). In commercial production, the high level of automation featured the efficiency requirements of mass 
production, while the significant customization requirements indicated a new kind of mass production emphasizing flexibility (Duguay et al., 1997; De Toni and Tonchia, 2002).

In Enerfi, prototypes were designed according to each customer's requirements and their development relied on the expertise of experienced workers: the production concept of building prototypes resembled craft. Simultaneously, Enerfi was developing a networked mass production concept that had characteristics of process enhancement or lean production (Pettersen, 2009). The aim was to design product-specific production lines to be transferred to a distant subcontractor whose actions could be monitored through an online reporting system.

Type 2 tensions were located between a product concept and a production concept. The companies were seeking a balance between customization and standardization of their products to respond to customers' requirements while producing the products costeffectively.

In Fipak, the hybrid package as a uniqueness-providing product concept was problematic due to the target customers' emphasis on cost-effectiveness and avoidance of investments in new production lines. The product concept that required customization of the manufacturing technology also collided with the company's target to build automatized mass production. To reduce product-specific tailoring of the production equipment, Fipak aimed to develop standardized packages that could be offered to multiple customers.

In Enerfi, the product concept was created to increase the performance of its customers' energy applications. However, these applications were competing with traditional energy production systems and their implementation depended on complicated industrial and political decision making processes. Due to the uncertainties in customers' projects, Enerfi's mass production concept was difficult to implement while the expansive potential of the prototype production as a genuine, project manufacturing, production concept had not been acknowledged (cf. Yang, 2013). Enerfi had started a standardization project to offer its customers a set of products that fulfilled the requirements of legislators and the standards of the industry. Still, the consequences of such product standardization for the networked production concept were unclear. 
Type 3 tensions concerned the companies' relationships with their customers, suppliers and other partners. In Fipak, collaboration with the customer was a necessary aspect of the product development concept, while in mass production the customer's role was smaller. Enerfi was dependent on one customer, whose products were in mass production, while products for other customers remained in the prototype testing phase waiting for investment decisions.

Both companies were facing challenges in the relationships with their subcontractors. In Fipak, the suppliers' expertise was acknowledged, but the team members questioned their genuine interest in deepening collaboration. In Enerfi, there was an obvious willingness to learn from the subcontractors' feedback, but current collaboration practices did not allow sufficient sharing of expertise. This was partly due to the concern of becoming too dependent on the competences of single suppliers. The network based tensions in both companies illustrate the challenges of moving from the logic of traditional mass production, based on hierarchical relationships and price competition, to the logic of flexible production, relying on collaboration with network partners (Duguay et al., 1997).

\section{From concept-level tensions to concept-level learning}

Companies search for novel and genuinely customer-centered production concepts to maintain competitiveness in global business. The involvement of customers and end users in the whole lifecycle of the product and its production is characterized as a co-configuration concept (Victor and Boynton, 1998). The move to co-configuration represents a concept-level change for companies; empirical examples of companies going through this transformation exhibit the process as complex and tension-laden (Virkkunen, 2006b). The case companies' contradictory relationships with their suppliers indicate that co-configuration, requiring longterm relationships with partners (Engeström, 2004), was still somewhat embryonic. The powerfulness of concepts was manifested by the dominance of "mass production", which partly restricted the workshop participants from envisioning new kinds of collaboration with partners crucial in co-configuration. 
Earlier research on concept-level transformations interprets the creation of a new production concept as a means to overcome "an aggravating inner contradiction within the prevailing one" (Virkkunen, 2007, 160). However, in the relatively young companies of our study these kinds of contradictions had not, as yet, culminated. Rather than implementing a crystallized production concept they were still searching for ways to organize their production activity, finding themselves between innovative product development and flexible mass production.

Our findings regarding two co-existing production concepts contrast with the tendency to raise one production concept at a time as universally applicable (cf. De Toni and Tonchia, 2002). In addition, our analysis of the relationships between production and product concepts shows the situatedness of local production concepts. Although both companies strived to move to mass production, their local production concepts differed according to the nature of their products: whereas one was constructing automation, the other was establishing a reconfigurable production network. Production concepts and product concepts were mutually developing and shaping each other. For example, Fipak attempted to adapt an innovative and customizable product concept to the requirements of the mass production concept. Its solution was to develop standard products along with customized products, which were created with the product development concept.

Our case companies' struggles with the concept-level tensions were, naturally, troublesome, but also provided developmental opportunities. Inconsistencies between craft and coconfiguration types of work, between customers' preferences and efficiency requirements of competitive production, etc., compelled the companies to develop original solutions to the aspired mass production concept. This suggests that tensions produced by co-existing production concepts may become triggers for concept-level learning. Collective examination of production concepts and their relationships with product concepts supports concept-level transformation; engagement in concept formation is a prerequisite for expansive learning in workplaces (Engeström et al., 2005).

Concept-level learning can entail both gradual refinement of practices and radical expansion of activity. The former connects with incremental, "exploitative" learning discussed in organization studies (March, 1991; Gupta et al., 2006) as well as with viewing learning as a by-product of producing goods or services in workplace studies (Fuller and Unwin, 2005). 
An example of gradual refinement was the execution of new product development projects until the mass production phase in Enerfi to refine the networked mass production concept, which we observed during our research collaboration. Further examples were seen in the workshops where Enerfi's participants viewed the development of shared tools as a key to the refinement of the production concept. An example of radical expansion was the creation of the hybrid package as an innovative product concept and the establishment of Fipak as a business unit. Another example was seen in the workshops where Fipak's participants identified an expansive learning need to solve the tensions between the customized product concept and the mass production concept.

To conclude, our analysis of the concept-level transformation and learning expands our understanding of workplace learning and bridges the gap between product development and operations management research. Concept-level learning requires the articulation and analysis of production and product concepts, but many companies may still today lack competencies to address the tensions involved. Sustainable expansion of activity calls for learning forums where tensions can be "mobilized" as triggers for concept-level learning. However, our study can make limited empirical conclusions of learning by network partners, because the partners did not participate in the workshops. We still believe that researchers may provide important contributions to organizations' collective development efforts by collaborating with practitioners. Future studies and intervention methods, such as Change Laboratory (Virkkunen and Newnham, 2013) and deliberately founded learning networks, may provide arenas for collective concept formation and enhance expansive learning among diverse participants (Toiviainen et al., 2009). We encourage new research exploring favorable conditions of concept-level learning at workplaces and developing interventions which engage network partners in mutual learning efforts.

\section{References}

Bateson, G. (2000), Steps to an Ecology of Mind (2000 ed.), University of Chicago Press, Chicago. 
Blackler, F., Crump, N. and McDonald, S. (1998), "Knowledge, organizations and competition", in von Krogh, G., Roos, J. and Kleine, D. (Eds.), Knowing in Firms: Understanding, Managing and Measuring Knowledge, Sage, London, pp. 67-86.

Da Silveira, G., Borenstein, D. and Fogliatto, F.S. (2001), "Mass customization: Literature review and research directions", International Journal of Production Economics, Vol. 72 No. 1, pp. 1-13.

De Toni, A. and Tonchia, S. (2002), "New production models: A strategic view", International Journal of Production Research, Vol. 40 No. 18, pp. 4721-4741.

Duguay, C.R., Landry, S. and Pasin, F. (1997), "From mass production to flexible/agile production", International Journal of Operations \& Production Management, Vol. 17 No. 12, pp. 1183-1195.

Engeström, Y. (1987), Learning by Expanding: An Activity-theoretical Approach to Developmental Research, Orienta konsultit, Helsinki.

Engeström, Y. (2004), "New forms of learning in co-configuration work", Journal of Workplace Learning, Vol. 16 No. 1/2, pp. 11-21.

Engeström, Y., Pasanen, A., Toiviainen, H. and Haavisto, V. (2005), "Expansive learning as collaborative concept formation at work", in Yamazumi, K., Engeström, Y. and Daniels, H. (Eds.), New Learning Challenges: Going beyond the Industrial Age System of School and Work, Kansai University Press, Osaka, pp. 47-77.

Fuller, A. and Unwin, L. (2005), “Older and wiser? Workplace learning from the perspective of experienced employees", International Journal of Lifelong Education, Vol. 24 No. 1, pp. 21-39.

Gunasekaran, A. and Ngai, E.W.T. (2012), "The future of operations management: An outlook and analysis", International Journal of Production Economics, Vol. 135 No. 2, pp. 687-701. 
Gupta, A. K., Smith, K. G. and Shalley, C. E. (2006), "The interplay between exploration and exploitation", Academy of Management Journal, Vol. 49 No. 4, pp. 693-706.

Hutchins, E. (2012), "Concepts in practice as sources of order", Mind, Culture, and Activity, Vol. 19 No. 3, pp. 314-323.

Kim, D.H. (2004), "The link between individual and organizational learning”, in Starkey, K., Tempest S. and McKinlay, A. (Eds.), How Organizations Learn: Managing the Search for Knowledge, Thomson, London, pp. 29-50.

March, J.G. (1991), "Exploration and exploitation in organizational learning", Organization Science, Vol. 2 No. 1, pp. 71-87.

Miettinen, R., Lehenkari, J. and Tuunainen, J. (2008), "Learning and network collaboration in product development: How things work for human use", Management Learning, Vol. 39 No. 2, pp. 203-219.

Moyano-Fuentes, J. and Sacristán-Díaz, M. (2012), "Learning on lean: a review of thinking and research", International Journal of Operations \& Production Management, Vol. 32 No. 5, pp. 551-582.

Nicolini, D., Gherardi, S. and Yanow, D. (2003), "Introduction: Toward a practice-based view of knowing and learning in organizations", in Nicolini, D., Gherardi, S. and Yanow, D. (Eds.), Knowing in Organizations: A Practice-based Approach, M.E. Sharpe, Armonk, NY, pp. 3-31.

Orihata, M. and Watanabe, C. (2000), "The interaction between product concept and institutional inducement: a new driver of product innovation", Technovation, Vol. 20 No. 1, pp. 11-23.

Pettersen, J. (2009), "Defining lean production: some conceptual and practical issues", The TQM Journal, Vol. 21 No. 2, pp. 127-142. 
Ravasi, D. and Stigliani, I. (2012), "Product design: a review and research agenda for management studies", International Journal of Management Reviews, Vol. 14 No. 4, pp. 464488.

Seidel, V.P. (2007), "Concept shifting and the radical product development process", Journal of Product Innovation Management, Vol. 24 No. 6, pp. 522-533.

Toiviainen, H. (2007), "Inter-organizational learning across levels: an object-oriented approach”, Journal of Workplace Learning, Vol. 19 No. 6, pp. 343-358.

Toiviainen, H., Kerosuo, H. and Syrjälä, T. (2009), ““'Development Radar”: the coconfiguration of a tool in a learning network", Journal of Workplace Learning, Vol. 21 No. 7, pp. 509-524.

Victor, B. and Boynton, A.C. (1998), Invented Here: Maximizing Your Organization's Internal Growth and Profitability, Harvard Business School Press, Boston, MA.

Virkkunen, J. (2006a), "Dilemmas in building shared transformative agency", Activités, Vol. 3 No. 1, pp. 44-66.

Virkkunen, J. (2006b), "Hybrid agency in co-configuration work", Outlines. Critical Practice Studies, Vol. 8, No. 1, pp. 61-75.

Virkkunen, J. (2007), "Collaborative development of a new concept for an activity", Activités, Vol. 4 No. 2, pp. 158-164.

Virkkunen, J. and Newnham D. (2013), The Change Laboratory. A Tool for Collaborative Development of Work and Education, Sense Publishers, Rotterdam.

Yang, L.-R. (2013), "Key practices, manufacturing capability and attainment of manufacturing goals: The perspective of project/engineer-to-order manufacturing", International Journal of Project Management, Vol. 31 No. 1, pp. 109-125. 